\title{
The occurrence and management of fluid retention associated with TKI therapy in CML, with a focus on dasatinib David Masiello, Gerry Gorospe III and Allen S Yang*
}

\author{
Address: Jane Anne Nohl Division of Hematology and Center for the Study of Blood Diseases, University of Southern California Medical Center, \\ 1441 Eastlake Ave Suite 7317, Los Angeles, CA 90033, USA \\ Email: David Masiello - masiello@usc.edu; Gerry Gorospe - gorospe@usc.edu; Allen S Yang* - allenyan@usc.edu \\ * Corresponding author
}

Published: 12 November 2009

Journal of Hematology \& Oncology 2009, 2:46 doi:10.1 186/1756-8722-2-46

This article is available from: http://www.jhoonline.org/content/2/1/46

(c) 2009 Masiello et al; licensee BioMed Central Ltd.

This is an Open Access article distributed under the terms of the Creative Commons Attribution License (http://creativecommons.org/licenses/by/2.0), which permits unrestricted use, distribution, and reproduction in any medium, provided the original work is properly cited.

\begin{abstract}
Tyrosine kinase inhibitors (TKIs) like dasatinib and nilotinib are indicated as second-line treatment for chronic myeloid leukemia resistant or intolerant to the current first-line TKI imatinib. These are agents are well tolerated, but potent and as such should be monitored for potentially serious side-effects like fluid retention and pleural effusions. Here we present key clinical trial data and safety considerations for all FDA approved TKIs in context for effective management of fluid retention and pleural effusions. Altering the dasatinib regimen from $70 \mathrm{mg}$ twice daily to $100 \mathrm{mg}$ daily reduces the risk of pleural effusion for patients taking dasatinib. Should pleural effusion develop, dasatinib should be interrupted until the condition resolves. Patients with a history of pleural effusion risk factors should be monitored closely while taking dasatinib. Patients receiving imatinib and nilotinib are not without risk of fluid retention. All patients should also be educated to recognize and report key symptoms of fluid retention or pleural effusion. Pleural effusions are generally managed by dose interruption/reduction and other supportive measures in patients with chronic myeloid leukemia receiving dasatinib therapy.
\end{abstract}

\section{Introduction}

Chronic myeloid leukemia (CML) is a hematopoietic stem cell malignancy with an age-adjusted incidence rate of 1.5 per 100,000 individuals per year within the United States, accounting for $15 \%$ of all adult leukemias $[1,2]$. The median age of diagnosis is 66, but CML may occur in all age groups [1]. CML typically progresses through three sequential phases: chronic phase (CP), accelerated phase (AP), and terminal blast crisis (BC). Most often, patients are diagnosed during $\mathrm{CP}$.

At the cellular level, CML is characterized by the presence of the Philadelphia $(\mathrm{Ph})$ chromosome [3]. This genetic abnormality results from a reciprocal translocation between chromosomes 9 and 22, leading to the formation of the pathogenic tyrosine kinase signal transduction protein, BCR-ABL [4-6]. BCR-ABL is also found in some patients with acute lymphoblastic leukemia $(\mathrm{Ph}+\mathrm{ALL})$.

If untreated, the prognosis for patients with CML is poor. Under these conditions the disease usually progresses from $\mathrm{CP}$ to $\mathrm{BC}$ within 3-5 years [2]. Even with the benefit of imatinib mesylate treatment, some patients with $\mathrm{CML}$ progress to $\mathrm{BC}$ [7]. Therefore, there is a strong medical need for effective treatments for this malignancy.

The treatment of CML was revolutionized by the use of tyrosine kinase inhibitors (TKIs) directed against BCR$\mathrm{ABL}$, the first developed being imatinib (Gleevec ${ }^{\circledast}$ ). Currently, imatinib remains the only FDA-approved first-line 
treatment option for this disease [8]. Imatinib has been shown to benefit most patients; however, resistance and intolerance to this agent have emerged as clinical concerns. These problems may either prevent a patient from attaining a sufficient clinical response (suboptimal response), or may cause a patient to lose an existing one (relapse). In the pivotal phase III study of imatinib, 23\% of patients faced initial, inherent (primary) resistance, and a further $4 \%$ of patients presented with intolerance to the agent $[9,10]$. After 7 years of follow-up, it was found that $40 \%$ of patients discontinued imatinib due to adverse events, lack of efficacy, bone marrow transplant, death, protocol violation, withdrawal of consent, loss of followup, or administrative reasons [11]. A large European retrospective survey found that $45 \%$ of all patients treated with imatinib displayed resistance or intolerance [12].

Reasons for imatinib resistance are multifactorial. The most understood mechanism is mutation of BCR-ABL, preventing imatinib from binding effectively to the protein [8]. It is thought to be the most important mechanism underlying secondary resistance. Other mechanisms include decreased intracellular levels of imatinib (caused by changed expression of drug efflux or influx proteins), increased levels of BCR-ABL (via gene amplification or over expression), or pathologic alteration of downstream intracellular pathways (e.g., SRC family kinases; SFKs).

Effective second-line treatments for imatinib-resistant or intolerant patients with CML are now available. Dasatinib $\left(\right.$ Sprycel $\left.^{\circledR}\right)$ and nilotinib (Tasigna ${ }^{\circledR}$ ) are both second-line TKIs approved for patients with CP or AP CML resistant or intolerant to imatinib. The drugs are similar in their ability to overcome resistance to imatinib therapy, but there are subtle differences in indications and side effect profiles that are worth mentioning. Nilotinib is associated with prolongation of the QT interval and therefore a screening EKG is recommended prior to starting therapy [13]. In addition, nilotinib administration requires the patient to fast prior to taking the twice daily dose. Dasatinib does not have a fasting or screening EKG requirement, but is associated with a higher incidence of pleural effusions [14]. Dasatinib is also indicated for the treatment of patients with BC CML or Ph+ ALL and who are resistant or intolerant to imatinib. It is important to note there are no direct comparisons of efficacy of nilotinib and dasatinib in CML.

Although both second-line TKIs are well tolerated, side effects do occur during treatment. Management of side effects is essential to ensure that patients continue treatment and have the best possible chance of a positive longterm outcome. In this review, we will focus on the the occurrence and appropriate management of pleural effusions during dasatinib therapy.

\section{Dasatinib}

Dasatinib is a thiazole carboximide with potent activity against BCR-ABL and also SFKs [15]. This agent has 325fold greater activity against unmutated BCR-ABL in vitro than imatinib, and displays activity in all but one of the known imatinib-resistant BCR-ABL mutations (i.e., T315I) [15-17]. Dasatinib has been demonstrated to be active and well tolerated in patients with imatinib resistance or intolerance across all phases of CML [18-20]. The current approved doses are $100 \mathrm{mg}$ once daily for patients with $\mathrm{CP} C \mathrm{CML}$, and $140 \mathrm{mg}$ once daily for patients with advanced (AP or BC) CML or Ph+ ALL. Dasatinib is available in $20 \mathrm{mg}, 50 \mathrm{mg}, 75 \mathrm{mg}$, and $100 \mathrm{mg}$ tablets, and may be swallowed whole, with or without a meal [13].

Dasatinib was originally approved across all phases of CML at a dosage of $70 \mathrm{mg}$ twice daily. In key phase II studies, marked responses were attained across all phases of CML using this schedule. For example, after a minimum follow-up of two years, complete cytogenetic responses (i.e., Ph was undetectable) were reached in more than half (53\%) of patients with CP CML [21]. These responses were mirrored by impressive rates of progression-free survival (80\%) and overall survival (94\%).

The recommended starting dose for patients with $\mathrm{CP} C \mathrm{CML}$ was changed from $70 \mathrm{mg}$ twice daily to $100 \mathrm{mg}$ once daily. This change was prompted by the results of a phase III dose optimization study in which the $100 \mathrm{mg}$ once-daily dose demonstrated improved tolerability, plus insignificantly changed efficacy, compared with the previously recommended $70 \mathrm{mg}$ twice-daily dose (discussed further below) [22]. The recommended starting dose for patients with advanced phase CML or Ph+ ALL remains $70 \mathrm{mg}$ twice daily.

\section{The Toxicities of Dasatinib}

The side effects associated with dasatinib therapy are predominantly mild or moderate (grade 1 or 2 by the National Cancer Institute Cancer Therapy Evaluation Program criteria), and are self-limiting or resolve following supportive care [18-20,22]. Dasatinib is associated with correspondingly positive rates of treatment compliance and toxicity-related withdrawal [18-20,22].

The phase III dose-optimization of dasatinib study showed that the incidence of key treatment-related side effects can be reduced, while maintaining the efficacy of dasatinib, by manipulating the dosage schedule. After a minimum follow-up of 6 months, major cytogenetic responses were attained in 59\% of patients receiving dasatinib $100 \mathrm{mg}$ once daily and in 55\% of patients receiving dasatinib $70 \mathrm{mg}$ twice daily [22]. Concomitantly, incidences of severe (grade 3-4) side effects were significantly reduced in the $100 \mathrm{mg}$ once-daily arm com- 
pared with the $70 \mathrm{mg}$ twice-daily arm (30\% vs. $48 \%$; $\mathrm{p}=$ 0.001). The most frequently occurring side effects of dasatinib are hematologic, as would be expected for a leukemia therapy. Notably, the number of patients experiencing grade 3-4 thrombocytopenia were also significantly lower in the $100 \mathrm{mg}$ once-daily arm (22\% vs. 37\%; $\mathrm{p}=0.004)$. The number of patients discontinuing dasatinib as a result of toxicity in the $100 \mathrm{mg}$ once-daily arm were correspondingly lower (4\% vs. 11\%).

The recurrence of side effects associated with imatinib intolerance is minimal, indicating that there is a lack of cross-intolerance in patients presenting with imatinib intolerance. After 8 months of follow-up in the pivotal phase II study in patients with CP CML, 7\% of patients with imatinib-intolerant CP CML discontinued treatment with dasatinib due to drug-related toxicity [20]. After a minimum of 24 months of follow-up, discontinuation rates for dasatinib in patients intolerant to imatinib due to hepatotoxicity $(0 \%)$, rash $(1 \%)$, and cytopenias $(6 \%)$ remained low [23].

\section{Pleural Effusion}

The incidences of grade 3-4 nonhematologic side effects in response to dasatinib treatment are minimal [18-20]. However, one of the more problematic nonhematologic side effects that can occur on dasatinib treatment is pleural effusion.

The incidence of grade 3-4 pleural effusion in patients with CP CML from collated studies was $4 \%(n=1150)$ [13]. This side effect is more common in patients with advanced disease. Incidence rates for grade 3-4 pleural effusion is $5 \%(\mathrm{n}=502)$ in AP CML, 10\% in myeloid BP CML, and $6 \%(n=280)$ in lymphoid BP CML or Ph+ ALL $(\mathrm{n}=250)$. Patients over the age of 65 years are more likely to experience fluid retention events, and should also be monitored closely [13]. The phase III dose-optimization study in patients with imatinib-resistant or -intolerant CP CML demonstrated that changing the dosage from $70 \mathrm{mg}$ twice daily to $100 \mathrm{mg}$ daily more than halves the inci- dence of any grade pleural effusion (16\% vs. $7 \%$, p = 0.024 ) (Table 1) [22].

The mechanism underlying the development of pleural effusions during dasatinib therapy is currently unclear, and it is possible that pleural effusions are multifactorial [24]. Pleural effusions may be related to fluid retention resulting from nonspecific inhibition of platelet-derived growth factor receptor- $\beta$ or other kinases [25]. There is also evidence that pleural effusions may be immunerelated, as shown by lymphocytic infiltration of pleural fluids and an association between effusions and immunemediated reactions, such as rash and autoimmune events $[24,26]$. It has been suggested that dasatinib may inhibit the function of normal T cells [27], and bind major regulators of the immune system [28]. Factors significantly related to the development of pleural effusion include a history of cardiac disease, hypertension, hypercholesterolemia, history of autoimmune disease, and history of skin rash during imatinib or dasatinib therapy [24,25].

Pleural effusions are potentially serious and must be treated promptly. To facilitate more rapid identification of pleural effusions, patients should also be educated to recognize and report relevant symptoms - i.e., chest pain, dyspnea and dry cough. In a study of patients who developed dasatinib-related pleural effusion ( $n=48)$, all patients reported dyspnea at the time pleural effusion was reported [25]. The grade of dyspnea correlated with the radiographic extent of pleural effusion. Also, 29\% of these patients also experienced pericardial effusion. Patients with a history of risk factors should be monitored closely, and measures, including optimizing blood pressure and serum cholesterol levels through medication, and performing a baseline chest x-ray, are also recommended.

Pleural effusions are generally managed by dose interruption/reduction, and supportive measures [2,25]. See Figure 1 for recommended management steps. Patients with CML exhibiting symptoms of pleural effusion should undergo radiographic testing. For confirmed incidences of

Table I: Incidence of pleural effusion in patients with CP CML with exposure to dasatinib

\begin{tabular}{|c|c|c|c|}
\hline & \multicolumn{2}{|c|}{ Dosage } & \multirow[b]{2}{*}{ P-value } \\
\hline & $\begin{array}{c}70 \mathrm{mg} \text { twice daily } \\
n=167\end{array}$ & $\begin{array}{c}100 \mathrm{mg} \text { once daily } \\
n=166\end{array}$ & \\
\hline \multicolumn{4}{|l|}{ Pleural effusion ${ }^{a}$} \\
\hline All grades & $26(16 \%)$ & $12(7 \%)$ & 0.024 \\
\hline Grades 3-4 & $2(1 \%)$ & $2(1 \%)$ & - \\
\hline
\end{tabular}

aClassifications are as follows: grade I, asymptomatic; grade 2, symptomatic, intervention with diuretics or up to two therapeutic thoracenteses indicated; grade 3, symptomatic and supplemental oxygen is required, greater than two therapeutic thoracenteses, tube drainage, or pleurodesis indicated; grade 4, life-threatening (e.g., causing hemodynamic instability); grade 5, death.

Data from Shah et al[22] 


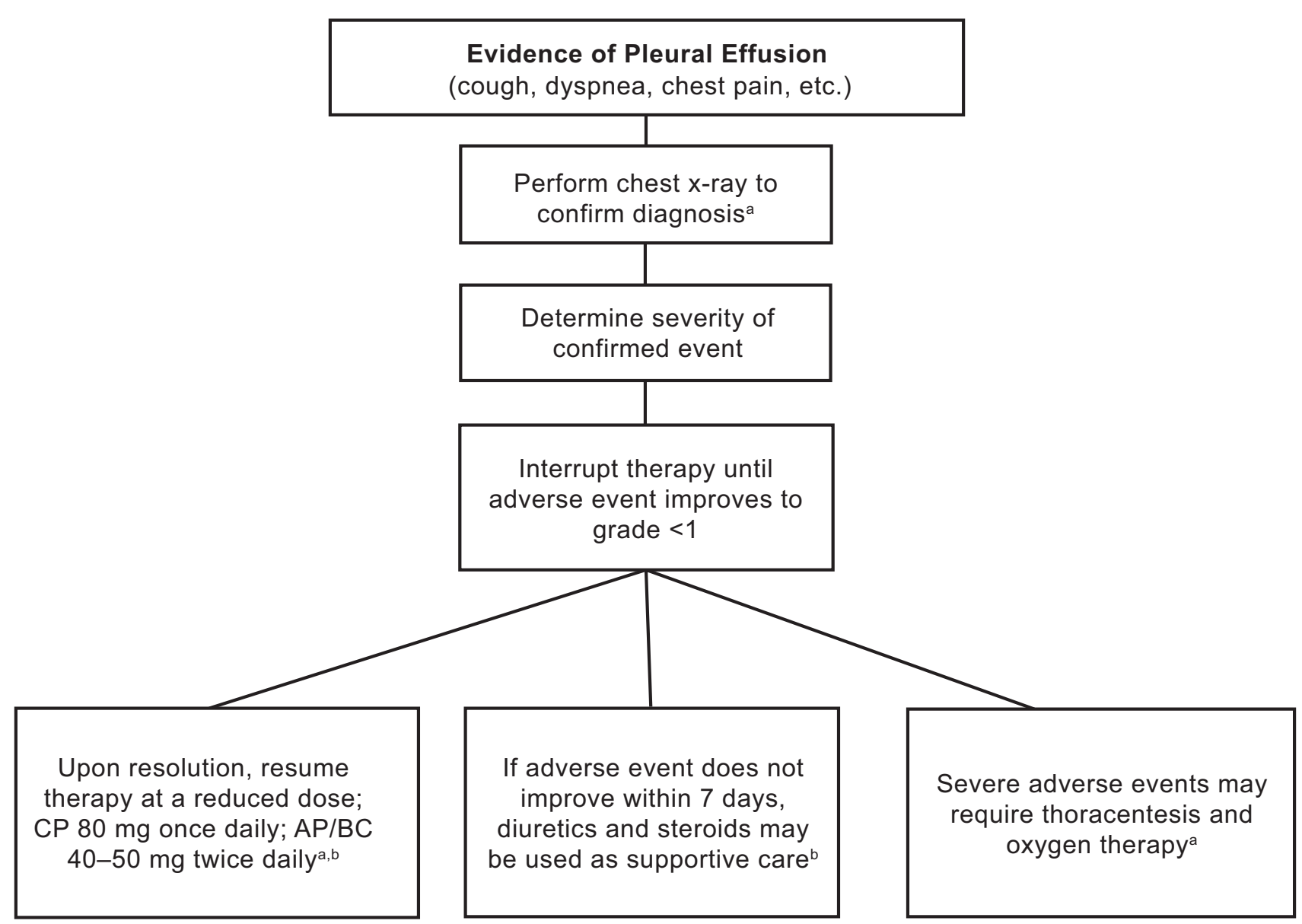

Figure I

The management of pleural effusion emerging on treatment with dasatinib. aBMS, 2009 [13]. bNCCN, 2009 [2]. Abbreviation: $\mathrm{ANC}=$ absolute neutrophil count

pleural effusion, therapy should be interrupted until the event improves and later resumed at a reduced dose. The use of diuretics and steroids may be warranted. If an immune-related mechanism is indeed responsible for pleural effusion occurring during dasatinib treatment, corticosteroids are likely to be more effective than diuretics as an adjunct to dose reduction/interruption $[26,29]$.

\section{Nilotinib}

Nilotinib, a derivative of imatinib, was approved by the FDA in late 2007 for the treatment of adult patients with CP or AP CML resistant or intolerant to prior therapy with imatinib. The activity of nilotinib (400 mg orally twice daily) in patients with all phases of CML resistant or intolerant to imatinib has been confirmed in phase II studies [30-32]. In a trial of 280 patients with CP CML, a MCyR rate of $48 \%$ was observed after 6 months of follow-up [31]. At 12 months, the estimated survival was $95 \%$.
Cross-intolerance between nilotinib and imatinib was minimal in these studies.

While imatinib has been commonly associated with grade 1-2 fluid retention $(59.9 \%$ in the multicenter phase III study that led to its approval), nilotinib is not as frequently associated with these events. Any-grade peripheral edema was reported in $11 \%$ of patients with $\mathrm{CP} C \mathrm{CML}$ receiving nilotinib, but none of these cases were severe [14]. Patients with AP CML experienced similar rates of edema. Pleural effusions is uncommonly associated with nilotinib therapy (1\%) [30]. Management of these AEs is best treated with dose interruptions, and therapy can be resumed at the $400 \mathrm{mg}$ once daily dose after resolution [14]. Besides fluid retention, other adverse events contribute to the safety profile of both imatinib and nilotinib, and HCPs should be familiar with these before initiating therapy. 


\section{Conclusion}

Currently three TKI therapies are available to patients with CML. Imatinib remains the recommended frontline therapy for patients with CP CML, but two new therapies, dasatinib and nilotinib, are available for CML patients who are resistant to or intolerant of imatinib therapy. Although the newer TKIs are similar, there are differences in their side-effects and indications. To date, there is no data comparing the efficacy of these three drugs directly, but these studies are currently ongoing. This article has focused specifically on the management of pleural effusions associated with dasatinib therapy. Fluid retention AEs have been associated with all three BCR-ABL inhibitors currently on the market, but pleural effusions may be more common with dasatinib therapy. These events are manageable, generally mild-to-moderate in severity, and occur more frequently in older patients (= 65 years) and/ or patients with advanced CML disease.

The current recommended regimen of dasatinib for patients with CP CML is $100 \mathrm{mg}$ once daily. This dose is associated with significantly fewer occurrences of key treatment-related side effects (including grade 3-4 pleural effusion) in comparison with the previously recommended regimen of $70 \mathrm{mg}$ twice-daily dasatinib. Dasatinib $70 \mathrm{mg}$ twice daily remains a highly effective treatment for patients with advanced CML and Ph+ ALL.

Clinical experience has shown that pleural effusions are generally reversible following a combination of dose interruption/reduction and additional supportive measures. In some rare cases more invasive steps like thoracocentesis or chest tubes are necessary to resolve the condition. In order to ensure appropriate management, patients should be vigilantly monitored for pleural effusions. Additionally, patients should be educated to recognize relevant symptoms of pleural effusions and other drug-related side effects and encouraged to report such symptoms to their physicians.

\section{Competing interests}

Consultant or Advisory Role: DM, Novartis, and BristolMyers Squibb. GG, Bristol-Myers Squibb. ASY, Celgene, Eisai, and Vion. Honoraria: DM, Novartis, and BristolMyers Squibb. GG, Bristol-Myers Squibb. ASY, BristolMyers Squibb, Celgene, and Eisai. Stock ownership: ASY, TherEpi. Research Funding: GG, Bristol-Myers Squibb. ASY, Celgene, Novartis, and Methylgene.

\section{Authors' contributions}

GG, DM, and AY contributed equally to the content and focus of the manuscript from its earliest conception. All authors read and approved the final edition.

\section{Acknowledgements}

The CML Program is sponsored by a grant from the Norris Foundation. The authors take full responsibility for the content of the paper but thank StemScientific, funded by Bristol-Myers Squibb, for assistance in compiling the published literature and in providing writing support in the form of editing, formatting, styling, and administrative tasks associated with preparation of this manuscript. Bristol-Myers Squibb did not influence the content of the manuscript, nor did the authors receive financial compensation for authoring the manuscript.

\section{References}

I. National Cancer Institute. US National Institutes of Health: Surveillance Epidemiology and End Results web site: Finding Cancer Statistics: Cancer Stat Fact Sheets: Chronic Myeloid Leukemia. [http://seer.cancer.gov/statfacts/html/cmyl.html]. National Cancer Institute Accessed August 20, 2008

2. National Comprehensive Cancer Network (NCCN): Chronic myelogenous leukemia V.2.2009. NCCN Clinical Practice Guidelines in Oncology. [http://www.nccn.org/professionals/ physician gls/PDF/cml.pdf]. Accessed September 20, 2009

3. Sawyers CL: Chronic myeloid leukemia. N Engl J Med 1999 , 340( I 7): I330- I340.

4. Bartram CR, de Klein A, Hagemeijer A, van Agthoven T, Geurts van Kessel A, Bootsma D, Grosveld G, Ferguson-Smith MA, Davies T, Stone M, Heisterkamp N, Stephenson JR, Groffen J: Translocation of c-abl oncogene correlates with the presence of a Philadelphia chromosome in chronic myelocytic leukaemia. Nature 1983, 306(5940):277-280.

5. Groffen J, Stephenson JR, Heisterkamp N, de Klein A, Bartram CR Grosveld : Philadelphia chromosomal breakpoints are clustered within a limited region, bcr, on chromosome 22 . Cell 1984, 36(I):93-99.

6. Lugo TG, Pendergast AM, Muller AJ, Witte ON: Tyrosine kinase activity and transformation potency of bcr-abl oncogene products. Science 1990, 247(4946): 1079-1082.

7. Alvarez $\mathrm{RH}$, Kantarjian $\mathrm{H}$, Cortes JE: The biology of chronic myelogenous leukemia: implications for imatinib therapy. Semin Hematol 2007, 44(I Suppl I):S4-SI4.

8. Kantarjian HM, Talpaz M, Giles F, O'Brien S, Cortes J: New insights into the pathophysiology of chronic myeloid leukemia and imatinib resistance. Ann Intern Med 2006, I 45( I 2):9| 3-923.

9. Druker BJ, Guilhot F, O'Brien SG, Gathmann I, Kantarjian H, Gattermann N, Deininger MW, Silver RT, Goldman JM, Stone RM, Cervantes F, Hochhaus A, Powell BL, Gabrilove JL, Rousselot P, Reiffers J, Cornelissen J], Hughes T, Agis H, Fischer T, Verhoef G, Shepherd J, Saglio G, Gratwohl A, Nielsen JL, Radich JP, Simonsson B, Taylor K, Baccarani M, So C, Letvak L, Larson RA, IRIS Investigators: Five-year follow-up of patients receiving imatinib for chronic myeloid leukemia. N Engl J Med 2006, 355(23):2408-24I7.

10. Hughes T, Branford S: Molecular monitoring of BCR-ABL as a guide to clinical management in chronic myeloid leukaemia. Blood Rev 2006, 20(I):29-4I.

II. O'Brien SG, Guilhot F, Goldman JM: International randomized study of interferon versus STI57 I (IRIS) 7-year follow-up: sustained survival, low rate of transformation and increased rate of major molecular response (MMR) in patients (pts) with newly diagnosed chronic myeloid leukemia in chronic phase (CMLCP) treated with imatinib (IM) [abstract I86]. Blood 2008, I I 2(I I):.

12. Steegman JL, Michallet M, Morra E, Marin D, Ossenkoppele GJ, Verhoef G, Kühr T, Björeman M, Sterckx M, Cerri K: Imatinib use in chronic phase CML in clinical practice: the UNIC study [abstract 7077]. J Clin Oncol 2008, 26(I5s):391s.

13. Nilotinib prescribing information 2007 [http:// www.pharma.us.novartis.com/product/pi/pdf/tasigna.pdf]. East Hanover, NJ: Novartis Pharmaceuticals Corporation

14. Dasatinib prescribing information 2009 [http://packagein serts.bms.com/pi/pi sprycel.pdf]. Princeton, NJ: Bristol-Myers Squibb Company

15. Lombardo LJ, Lee FY, Chen P, Norris D, Barrish JC, Behnia K, Castaneda S, Cornelius LA, Das J, Doweyko AM, Fairchild C, Hunt JT, Inigo I, Johnston K, Kamath A, Kan D, Klei H, Marathe P, Pang S, Peterson R, Pitt S, Schieven GL, Schmidt RJ, Tokarski J, Wen ML, Wityak J, Borzilleri RM: Discovery of N-(2-chloro-6-methyl-phe- 
nyl)-2-(6-(4-(2-hydroxyethyl)-piperazin-I-yl)-2-

methylpyrimidin-4-ylamino)thiazole-5-carboxamide (BMS354825), a dual SrclAbl kinase inhibitor with potent antitumor activity in preclinical assays. J Med Chem 2004, 47(27):6658-666I.

16. O'Hare T, Walters DK, Stoffregen EP, Jia T, Manley PW, Mestan J, Cowan-Jacob SW, Lee FY, Heinrich MC, Deininger MW, Druker B]: In vitro activity of Bcr-Abl inhibitors AMNIO7 and BMS354825 against clinically relevant imatinib-resistant $A b \mid$ kinase domain mutants. Cancer Res 2005, 65(I I):4500-4505.

17. O'Hare T, Eide CA, Deininger MW: Bcr-Abl kinase domain mutations, drug resistance, and the road to a cure for chronic myeloid leukemia. Blood 2007, I l 0(7):2242-2249.

18. Cortes J, Rousselot P, Kim DW, Ritchie E, Hamerschlak N, Coutre S, Hochhaus A, Guilhot F, Saglio G, Apperley J, Ottmann O, Shah N, Erben P, Branford S, Agarwal P, Gollerkeri A, Baccarani M: Dasatinib induces complete hematologic and cytogenetic responses in patients with imatinib-resistant or -intolerant chronic myeloid leukemia in blast crisis. Blood 2007, 109(8):3207-32। 3.

19. Guilhot F, Apperley J, Kim DW, Bullorsky EO, Baccarani M, Roboz G], Amadori S, de Souza CA, Lipton JH, Hochhaus A, Heim D, Larson RA, Branford S, Muller MC, Agarwal P, Gollerkeri A, Talpaz M: Dasatinib induces significant hematologic and cytogenetic responses in patients with imatinib-resistant or -intolerant chronic myeloid leukemia in accelerated phase. Blood 2007, 109(10):4|43-4I50.

20. Hochhaus A, Kantarjian HM, Baccarani M, Lipton JH, Apperley JF, Druker BJ, Facon T, Goldberg SL, Cervantes F, Niederwieser D, Silver RT, Stone RM, Hughes TP, Muller MC, Ezzeddine R, Countouriotis AM, Shah NP: Dasatinib induces notable hematologic and cytogenetic responses in chronic phase chronic myeloid leukemia after failure of imatinib therapy. Blood 2007, 109(6):2303-2309.

21. Mauro MJ, Baccarani M, Cervantes F, Lipton JH, Matloub Y, Sinha R, Stone RM: Dasatinib 2-year efficacy in patients with chronicphase chronic myelogenous leukemia (CML-CP) with resistance or intolerance to imatinib (START-C) [abstract 7009]. J Clin Oncol 2008, 26( I5s):374s.

22. Shah NP, Kantarjian HM, Kim DW, Réa D, Dorlhiac-Llacer PE, Milone $\mathrm{JH}$, Vela-Ojeda J, Silver RT, Khoury HJ, Charbonnier A, Khoroshko N Paquette RL, Deininger M, Collins RH, Otero I, Hughes T, Bleickardt E, Strauss L, Francis S, Hochhaus A: Intermittent target inhibition with dasatinib $100 \mathrm{mg}$ once daily preserves efficacy and improves tolerability in imatinib-resistant and -intolerant chronic-phase chronic myeloid leukemia. J Clin Oncol 2008 26(19):3204-3212.

23. Khoury HJ, Goldberg SL, Mauro M, Stone RM, Matloub Y, Chen T, Guilhot F: Dasatinib lack of cross intolerance to imatinib in patients (pts) with chronic myelogenous leukemia chronic phase (CML-CP) intolerant to imatinib: a retrospective analysis of safety [abstract 70 I 5]. I Clin Oncol 2008, 26(I5s):375s.

24. de Lavallade H, Punnialingam S, Milojkovic D, Bua M, Khorashad JS, Gabriel IH, Chaidos A, Olavarria E, Goldman JM, Apperley JF, Marin $D$ : Pleural effusions in patients with chronic myeloid leukaemia treated with dasatinib may have an immune-mediated pathogenesis. Br J Haematol 2008, I 4 I(5):745-747.

25. Quintas-Cardama A, Kantarjian H, O'Brien S, Borthakur G, Bruzzi J, Munden R, Cortes J: Pleural effusion in patients with chronic myelogenous leukemia treated with dasatinib after imatinib failure. J Clin Oncol 2007, 25(25):3908-3914.

26. Bergeron A, Rea D, Levy V, Picard C, Meignin V, Tamburini J, Bruzzoni-Giovanelli H, Calvo F, Tazi A, Rousselot P: Lung abnormalities after dasatinib treatment for chronic myeloid leukemia: a case series. Am J Respir Crit Care Med 2007, I 76(8):8|4-8I8.

27. Blake S, Hughes TP, Mayrhofer G, Lyons AB: The Src/ABL kinase inhibitor dasatinib (BMS-354825) inhibits function of norma human T-lymphocytes in vitro. Clin Immunol 2008 , I 27(3):330-339.

28. Rix U, Hantschel O, Durnberger G, Remsing Rix LL, Planyavsky M, Fernbach NV, Kaupe I, Bennett KL, Valent P, Colinge J, Köcher T, Superti-Furga G: Chemical proteomic profiles of the BCR-ABL inhibitors imatinib, nilotinib, and dasatinib reveal novel kinase and nonkinase targets. Blood 2007, I I 0( I 2):4055-4063.

29. Hochhaus A: Management of Bcr-Abl-positive leukemias with dasatinib. Expert Rev Anticancer Ther 2007, 7(I I): 1529-1536.
30. Kantariian HM, Giles F, Gattermann N, et al.: Nilotinib (formerly AMN 107), a highly selective BCR-ABL tyrosine kinase inhibitor, is effective in patients with Philadelphia chromosomepositive chronic myelogenous leukemia in chronic phase following imatinib resistance and intolerance. Blood 2007, I 1 0:3540-3546.

3I. Le Coutre P, Larson R, Kantarjian H, et al:: A phase II study of nilotinib, a novel tyrosine kinase inhibitor administered to imatinib-resistant or -intolerant patients with Philadelphiapositive chronic myelogenous leukemia in accelerated phase. Haematologica 2007, 92(suppI I):557.

32. Ottmann $\mathrm{O}$, Larson $\mathrm{R}$, Kantarjian $\mathrm{H}$, et al.: Nilotinib monotherapy in patients with imatinib-resistant or -intolerant $\mathbf{P h}+$ chronic myelogenous leukemia (CML) in blast crisis or relapsed/ refractory $\mathbf{P h}+$ acute lymphoblastic leukemia. Haematologica 2007, 92(suppI I):556
Publish with Biomed Central and every scientist can read your work free of charge

"BioMed Central will be the most significant development for disseminating the results of biomedical research in our lifetime. "

Sir Paul Nurse, Cancer Research UK

Your research papers will be:

- available free of charge to the entire biomedical community

- peer reviewed and published immediately upon acceptance

- cited in PubMed and archived on PubMed Central

- yours - you keep the copyright
BioMedcentral 